\title{
Knowledge, Attitude, and Associated Factors towards Nonpharmacological Pain Management among Nurses Working at Amhara Region Comprehensive Specialized Hospitals, Ethiopia
}

\author{
Esayas Alemshet Tekletsadik, ${ }^{1}$ Abebaw Alemayehu Desta, ${ }^{1}$ \\ and Belayneh Shetie Workneh ${ }^{2}{ }^{2}$ \\ ${ }^{1}$ Department of Surgical Nursing, School of Nursing, College of Medicine and Health Sciences, University of Gondar, \\ Gondar, Ethiopia \\ ${ }^{2}$ Department of Emergency and Critical Care Nursing, School of Nursing, College of Medicine and Health Sciences, \\ University of Gondar, Gondar, Ethiopia
}

Correspondence should be addressed to Belayneh Shetie Workneh; belay2319@gmail.com

Received 9 August 2021; Accepted 18 November 2021; Published 30 November 2021

Academic Editor: Bekele Tesfaye

Copyright (c) 2021 Esayas Alemshet Tekletsadik et al. This is an open access article distributed under the Creative Commons Attribution License, which permits unrestricted use, distribution, and reproduction in any medium, provided the original work is properly cited.

\begin{abstract}
Background. Nonpharmacological pain management refers to providing pain management intervention that does not involve the use of drugs. Effective management of a patient's pain is a vital nursing activity, and it needs a nurse's adequate pain-related knowledge and a favorable attitude. Globally, many studies stated that the lack of knowledge and unfavorable attitude of nurses towards nonpharmacological pain management was the prevailing persistent challenge. Objective. To assess knowledge, attitude, and associated factors towards nonpharmacological pain management among nurses working in Amhara region Comprehensive Specialized Hospitals, Ethiopia, 2021. Method. An institutional-based cross-sectional study was conducted from April to May 30 , 2021. A total of 845 nurses were selected using a simple random sampling technique. Data were collected by using a pretested selfadministered structured questionnaire. Then, data were checked, coded, and entered into Epi Info version 7.0 and exported to SPSS version 25.0 software for analysis. Results. A total of 775 nurses participated in this study, with a response rate of $91.8 \%$. Of the total participants, $54.2 \%$ (95\% CI: 50.6-57.9) and 49.8\% (95\% CI: 46.1-53.2) of nurses had adequate knowledge and a favorable attitude, respectively. The study revealed that educational status ( $\mathrm{AOR}=3.51$ (95\% CI: 1.37, 8.99)), years of experience $(\mathrm{AOR}=5.59(95 \% \mathrm{CI}: 2.86,10.94))$, working unit $(\mathrm{AOR}=5.61(95 \% \mathrm{CI}: 2.25,13.96))$, nurse-to-patient ratio $(\mathrm{AOR}=2.33(95 \% \mathrm{CI}$ : $1.44,3.78)$ ), and working hours $(\mathrm{AOR}=2.15(95 \% \mathrm{CI}: 1.27,3.62))$ were significantly associated. This finding also revealed that monthly income $(\mathrm{AOR}=4.38$ (95\% CI: 1.64, 11.69)), nurse-to-patient ratio (AOR=1.89 (95\% CI: 1.19, 3.01)), and nurses' adequate knowledge ( $\mathrm{AOR}=4.26$ (95\% CI: 2.91, 6.24)) were significantly associated with the attitude of nurses. Conclusion and Recommendations. More than half and nearly half of the nurses had adequate knowledge and a favorable attitude towards nonpharmacological pain management, respectively. Educational qualification, years of experience, working unit, nurse-topatient ratio, and prolonged working hours per day were significantly associated with nurse's adequate knowledge. Monthly income, nurse-to-patient ratio, and nurse's knowledge were significantly associated with the attitudes of nurses. It is better to give attention to reviewing the nursing curriculum, achieving a standardized nurse-to-patient ratio, recruiting additional nurses, training, and upgrading nurses with continuing education.
\end{abstract}

\section{Introduction}

Pain is defined as "an unpleasant sensory and emotional experience associated with actual or potential tissue damage" $[1,2]$. Nonpharmacological pain management (NPPM) refers to the utilization of pain management alternatives other than pharmacological therapies such as physical therapy, occupational therapy, comfort therapy, psychosocial therapy, or counseling for the better management and reduction of pain $[3,4]$. 
Globally, many studies stated that lack of knowledge and unfavorable attitude of nurses towards NPPM was the prevailing persistent challenge [5]. Effective management of a patient's pain is a vital nursing activity, and it needs a nurse's adequate pain-related knowledge and a favorable attitude [6]. Nurse's knowledge and attitude have a significant effect on the use of NPPM. Different studies show that, among nurses who have inadequate knowledge and an unfavorable attitude towards NPPM, the majority of them did not use NPPM [7]. Moreover, among previous studies conducted regarding NPPM, 90\% of them had no documented evidence of the use of nonpharmacological pain interventions to alleviate pain [8].

This enormous gap negatively affects a collective of hospitalized patients' physical, emotional, and spiritual wellbeing, alters the quality of life of patients, increases the incidence and severity of complications, and increases healthcare costs [9]. Ineffectively managed pain affects the patient's quality of life negatively, which results in higher hospital readmission rate, more repeated outpatient visits, prolonged hospital stay, increased risk of nosocomial infection, and also increased stress and anxiety for the patient as well as his family $[10,11]$.

Most of the patients who lived with pain use opioids and long-term use of these drugs have an impact on the life of the patient; they can cause dependence, impaired memory, drowsiness, tolerance, lack of concentration, and poor judgment [12]. Therefore, NPPM strategies have more advantages for managing mild to severe pain than pharmacological pain management because NPPM is cost-effective, easy to provide for patients, has high potential to relieve the patient's pain, and can be used in combination with drugs or alone [13]. According to previous studies, nurses can acquire additional knowledge of NPPM through work experience, on-the-job training, and interaction with colleagues [14].

CDC recommends nonpharmacological interventions as a first-line approach for the treatment of mild to moderate pain, but opioids are the most commonly used currently [15]. Previously, few healthcare institutions in Ethiopia tried to implement important NPPM methods [8]. However, little was known about nurses' knowledge and attitude towards NPPM. Most of the studies conducted before included a single institution and working unit, while pain management is the concern of multiple institutions and working units. Therefore, the main aim of this study was to assess nurses' knowledge, attitudes, and factors associated with nonpharmacological pain management among nurses working in Amhara region Comprehensive Specialized Hospitals in 2021.

\section{Methods}

2.1. Study Design. An institutional-based cross-sectional study design was employed.

2.2. Study Area and Period. The study was conducted from March to April 30, 2021, at Comprehensive Specialized Hospitals in the Amhara regional state. According to the
Amhara National Regional Health Bureau's Annual Performance Report, the region has 81 hospitals, 858 health centers, and 3560 health posts. Among those 81 hospitals in the region, the University of Gondar, Dessie, Felege-Hiwot, Tibebe-Ghion, Debre Markos, Woldia, Debre Tabor, and Debreberhan are Comprehensive Specialized Hospitals. At the time of conducting this study, 1985 nurses were working in those hospitals. Thus, all those eight comprehensive specialized hospitals serve the population found in the region [16].

2.3. Population. All nurses working in Amhara regional state Comprehensive Specialized Hospitals were the source population. All nurses who were working in selected Comprehensive Specialized Hospitals during the data collection period were the study population.

\subsection{Eligibility Criteria}

2.4.1. Inclusion Criteria. All nurses who were working in selected Comprehensive Specialized Hospitals during the data collection period were included.

2.4.2. Exclusion Criteria. Those nurses who were seriously ill (unable to respond) were excluded from the study.

2.5. Sample Size Determination. The sample size was determined by using the single population proportion formula by taking the proportion of knowledge (51.2\%) and the favorable attitude (47\%) [8], 95\% confidence interval, and $5 \%$ marginal error.

$$
n=\frac{(Z a / 2)^{2} * P(1-P)}{d^{2}},
$$

where $n$ is the required sample size, $Z a / 2$ is the standard normal deviation at $95 \% \mathrm{CI}, P$ is the proportion of knowledge $(51.2 \%), d$ is margin of error that can be tolerated $(5 \%)$, and $1-p$ is the proportion of the population that does not possess the character of interest.

Therefore,

$$
n=\frac{(Z a / 2)^{2} * P(1-P)}{d^{2}}=\frac{(1.96)^{2} * 0.512(1-0.512)}{(0.05)^{2}}=384 \text {, }
$$

whereas the calculated sample size for the second dependent variable (attitude) was 383 .

To obtain a maximum sample size, a large number from the computed sample sizes were taken. Therefore, from the calculated sample sizes, the largest was 384. Since the sampling technique was multistage simple random sampling, the design effect was considered. So the sample size was multiplied by the number of stages (i.e., 2) and gives 768 . The final sample size was 845 after using the design effect and adding a $10 \%$ nonresponse rate. 


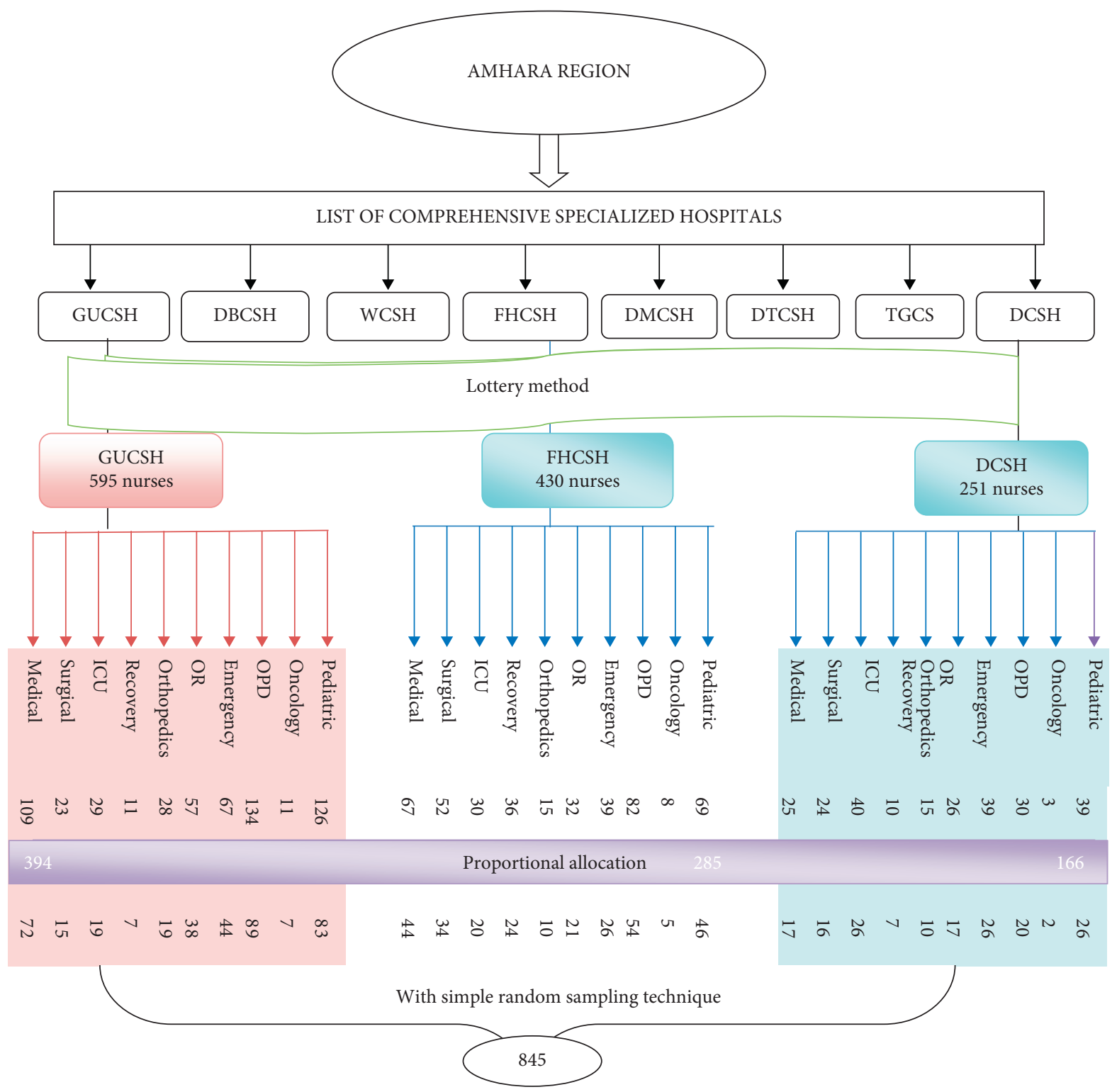

FIGURE 1: Schematic presentation of sampling procedure on knowledge, attitude, and associated factors of nurses towards non-pharmacological pain management among nurses working at Amhara region Comprehensive Specialized Hospitals, Ethiopia, 2021.

2.6. Sampling Technique and Procedure. A simple random sampling technique was used to select the study participants. Among the eight government Comprehensive Specialized Hospitals which are found in the Amhara region (Gondar University Comprehensive Specialized Hospital, Debre Markos Comprehensive Specialized Hospital, Felege-Hiwot Comprehensive Specialized Hospital, Debreberhan Comprehensive Specialized Hospital, Tibebe-Ghion Comprehensive Specialized Hospital, Debre Tabor Comprehensive Specialized Hospital, Woldia Comprehensive Specialized Hospital, and Dessie Comprehensive Specialized Hospital), three Comprehensive Specialized Hospitals (Gondar University Comprehensive Specialized Hospital, Dessie Comprehensive Specialized Hospital, and Felege-Hiwot Comprehensive Specialized Hospital) were selected with lottery method. Then, the total sample size was proportionally allocated for each working unit of the selected hospitals in which nurses are working (Figure 1).

\subsection{Operational Definitions}

Adequate knowledge: nurses who had scored median and above on the knowledge-related questions were considered as having adequate knowledge

Inadequate knowledge: those nurses who scored below the median on the knowledge questions were considered as having inadequate knowledge

Favorable attitude: nurses who had scored median and above on the attitude-related questions were considered as having a positive attitude 
Unfavorable attitude: nurses who had scored below the median on the attitude-related questions were considered as having a negative attitude

2.8. Data Collection Instruments and Procedures. A structured self-administered questionnaire (NKASRP) adapted from other similar studies was used to collect the data $[8,17-19]$. The questionnaires were prepared in English in the form of closed-ended questions. The questionnaires had four sections. The $1^{\text {st }}$ section was composed of 12 sociodemographic characteristics of participants including age, sex, educational status, year of experience, and formal training regarding nonpharmacological pain management. The $2^{\text {nd }}$ section was composed of 20 questions that assessed the knowledge of participants. The $3^{\text {rd }}$ section was composed of 18 questions with a Likert scale which assessed the attitude of nurses, and the $4^{\text {th }}$ section was composed of 19 facilityrelated questions.

Seven clinical nurses for the data collection and three BSc nurses for supervisors were recruited. One-day training for data collectors and supervisors was delivered by the principal investigator before the beginning of data collection regarding the objectives of the study, the data collection approach, the contents and relevance of the study, the confidentiality of the information, as well as the rights of participants. Simple random sampling method was used to get participants. Then, after eight hundred forty-five questionnaires were distributed, eight hundred nineteen were returned. During data collection, data collectors and supervisors followed the recommended precautions to prevent COVID-19.

2.9. Data Processing and Analysis. Data clean-up and checking were done before the analysis. Checked, cleaned, and coded data were entered into Epi Info version 7.0 and exported to SPSS version 25 for analysis. Reverse coding was done for negative questions to get consistent effects of measurement items. Descriptive statistics like frequencies, percentages, and tables were used to present the data. First, bivariable relationships between each independent variable and the dependent variable were investigated using a binary logistic regression model. Independent variables with a $p$ value $<0.25$ were included in multivariable analysis to control potential confounding factors. Finally, those variables with a $p$ value $<0.05$ with a $95 \%$ confidence interval were regarded as factors significantly associated.

2.10. Data Quality Assurance. The self-administered questionnaire was pretested by taking $5 \%$ of the sample size before the actual data collection time at Debre Tabor Comprehensive Specialized Hospital. After the pretest was conducted, amendments on the instrument, such as unclear questions and ambiguous words, were checked accordingly. Data collectors and supervisors were recruited, and one-day training was given on the objective of the study, instrument, and data collection procedures by the principal investigator.
TABle 1: Sociodemographic characteristics of nurses working at Amhara region Comprehensive Specialized Hospitals, Ethiopia, in $2021(N=775)$.

\begin{tabular}{lccc}
\hline Variables & Category & Frequency & Percent \\
\hline Age & 21-29 years & 327 & 42.2 \\
$M=30$ & 30-39 years & 346 & 44.6 \\
$\mathrm{IQR}=28-35$ & $40-49$ years & 94 & 12.1 \\
$R=23-57$ & $>50$ years & 8 & 1 \\
\hline Sex & Male & 332 & 42.8 \\
& Female & 443 & 57.2 \\
\hline Religion & Orthodox & 507 & 65.4 \\
& Protestant & 78 & 10.1 \\
& Muslim & 163 & 21 \\
& Others & 27 & 3.5 \\
\hline Marital status & Single & 299 & 38.6 \\
& Married & 429 & 55.4 \\
& Divorced & 33 & 4.3 \\
& Windowed & 14 & 1.8 \\
\hline Monthly income & $<5358$ ETB & 341 & 44 \\
$M=6000$ & $5358-6193$ ETB & 110 & 14.2 \\
IQR $=2100$ & 6193-7071 ETB & 151 & 19.5 \\
$R=3600-11600$ & $7071-8017$ ETB & 113 & 14.6 \\
& $>8017$ ETB & 60 & 7.74 \\
\hline
\end{tabular}

$\mathrm{ETB}=$ Ethiopian birr; $M=$ mean; $\mathrm{SD}=$ standard division; $R=$ range.

Supervision was conducted by the principal investigator and supervisors. To ensure data quality, each data collector checked the questionnaire from each study participant for completeness on a daily basis. The supervisors and principal investigator reviewed each questionnaire daily and checked for completeness. Cronbach's alpha value was done to check its reliability, and the knowledge item scored 0.751 and the attitude item scored 0.882 .

\section{Results}

3.1. Sociodemographic Characteristics of the Respondents. A total of 775 nurses participated in this study, with a $91.8 \%$ response rate. More than half $(57.2 \%)$ of the respondents were females, and $55.4 \%$ of them were married. The median age of study participants was 30 years with an IQR of 28-35, and the minimum and maximum ages of respondents were 23 and 57, respectively, and three hundred forty-six (44.6\%) of the study participants fall into the age category between 30 and 39 years. Concerning the monthly salary, three hundred forty-two $(44.1 \%)$ of participants earned a monthly income of $<5358$ Ethiopian birr (Table 1).

3.2. Professional and Organizational Related Factors. Out of the total respondents, $299(38.6 \%)$ reported that the nurseto-patient ratio in their working unit was undetermined, while $236(30.5 \%)$ reported a nurse-to-patient ratio of $1: 4$. Of the total participants, about half $(395,51 \%)$ reported that there was no pain assessment tool in their working units. Nearly two-thirds $(586,75.6 \%)$ of the study participants had no previous training on nonpharmacological pain management. Of the total participants, $546(70.5 \%)$ reported the presence of workload in their working unit, and 128 (16.5\%) 
TABle 2: Professional and organizational related factors among nurses working at Amhara region Comprehensive Specialized Hospitals, Ethiopia, in $2021(N=775)$.

\begin{tabular}{|c|c|c|c|}
\hline Variables & Category & Frequency & Percent \\
\hline \multirow[t]{4}{*}{ Nurse-to-patient ratio } & $1: 4$ & 236 & 30.5 \\
\hline & $1: 6$ & 99 & 12.8 \\
\hline & $1: 8$ & 141 & 18.2 \\
\hline & Undetermined & 299 & 38.6 \\
\hline \multirow[t]{2}{*}{ Presence of workload } & Yes & 546 & 70.5 \\
\hline & No & 229 & 29.5 \\
\hline \multirow[t]{2}{*}{ Is there NPPM equipment? } & Yes & 319 & 41.2 \\
\hline & No & 456 & 58.8 \\
\hline \multirow[t]{2}{*}{ NPPM guideline } & Yes & 516 & 66.6 \\
\hline & No & 259 & 33.4 \\
\hline \multirow[t]{2}{*}{ Lack of evidence } & Yes & 400 & 51.6 \\
\hline & No & 375 & 48.4 \\
\hline \multirow[t]{3}{*}{ Working hours } & 8 hours & 431 & 55.6 \\
\hline & $9-12$ hours & 216 & 27.9 \\
\hline & $>12$ hours & 128 & 16.5 \\
\hline \multirow[t]{2}{*}{ Pain assessment tool } & Yes & 380 & 49 \\
\hline & No & 395 & 51 \\
\hline \multirow{2}{*}{$\begin{array}{l}\text { Do you have training on } \\
\text { NPPM? }\end{array}$} & Yes & 189 & 24.4 \\
\hline & No & 586 & 75.6 \\
\hline \multirow{2}{*}{$\begin{array}{l}\text { Previous education on } \\
\text { NPPM? }\end{array}$} & Yes & 415 & 53.5 \\
\hline & No & 360 & 46.5 \\
\hline \multirow[t]{2}{*}{ Have you ever used NPPM? } & Yes & 608 & 78.5 \\
\hline & No & 167 & 21.5 \\
\hline \multirow[t]{3}{*}{ Educational qualification } & Diploma & 225 & 29 \\
\hline & $\mathrm{BSc}$ & 462 & 59.6 \\
\hline & $\mathrm{MSc}$ & 88 & 11.4 \\
\hline \multirow[t]{4}{*}{ Years of experience } & $<1$ year & 140 & 18.1 \\
\hline & $1-3$ years & 144 & 18.6 \\
\hline & $3-5$ years & 133 & 17.2 \\
\hline & $>5$ years & 358 & 46.2 \\
\hline \multirow[t]{10}{*}{ Working unit } & Pediatrics & 146 & 18.8 \\
\hline & Oncology & 14 & 1.8 \\
\hline & OPD & 151 & 19.5 \\
\hline & Emergency & 90 & 11.6 \\
\hline & OR & 76 & 9.8 \\
\hline & Orthopedics & 38 & 4.9 \\
\hline & Recovery & 32 & 4.1 \\
\hline & ICU & 58 & 7.5 \\
\hline & Medical ward & 117 & 15.1 \\
\hline & Surgical ward & 53 & 6.8 \\
\hline
\end{tabular}

worked more than 12 hours per day. Among the participants, four hundred sixty-two $(462,59.6 \%)$ were degree holders, and eighty-eight $(88,11.4 \%)$ were master's degree holders. Of the total participants, $53.5 \%$ of the respondents were attending courses on nonpharmacological pain management, and about $78.5 \%$ of the study participants reported that they had previously used this kind of pain management method (Table 2).

3.3. Knowledge of Nurses regarding Nonpharmacological Pain Management. Out of the twenty knowledge test questions distributed to the respondents regarding nonpharmacological pain management, $54.2 \%$ of nurses (95\% CI: $50.6,57.9)$ had adequate knowledge regarding nonpharmacological pain management with a total median knowledge score of $70 \%$. Out of the total twenty knowledge-related questions, the minimum score was 4 and the maximum score was 20 with a median score of 14 (IQR, 12-18) (Table 3).

3.4. The Attitude of Nurses towards Nonpharmacological Pain Management. Of the total of 775 participants, this study showed that $49.8 \%$ (95\% CI: $46.1,53.2)$ of the study participants had a favorable attitude regarding nonpharmacological pain management with a total median attitude score of $70 \%$. Of the eighteen Likert scale attituderelated questions, the minimum score was 37 and the maximum score was 90 with a median attitude score of 63 (IQR, 56-79). Among the total participants, 379 (48.9\%) strongly agreed with the idea that nurses are the best judges of the patient's pain intensity than doctors because they spend 24 hours with the patient, and 253 (32.6\%) agreed with the idea of nurses' willingness to provide nonpharmacological methods of pain management to patients who have pain (Table 4).

3.5. Factors Associated with Nurses' Knowledge. In bivariable logistic regression analysis, age, monthly income, educational status, year of experience, previous education on nonpharmacological pain management, working unit, nurse-to-patient ratio, workload, lack of evidence, training, and working hours were associated with knowledge. In multivariable logistic regression analysis, educational status, year of experience, working unit, nurse-to-patient ratio, and working hours were found to be significantly associated.

MScholders were nearly four times more likely $(\mathrm{AOR}=3.51(1.37-8.99))$ to have adequate knowledge as compared with diploma nurses, and BSc nurses were nearly three times more likely $(\mathrm{AOR}=2.86(1.80-4.56))$ to have adequate knowledge as compared to diploma nurses. Nurses who work in an emergency department were five $(\mathrm{AOR}=5.10(2.57,10.11))$ times more likely to have adequate knowledge as compared to those who work in the pediatrics unit. Nurses who reported a nurse-to-patient ratio of $1: 4$ in their working unit were two times more likely $(\mathrm{AOR}=2.33(1.44,3.78)$ to have adequate knowledge compared with those who reported an undetermined nurseto-patient ratio in their working units. Whereas nurses who reported a working hour of 8 hours per day $(\mathrm{AOR}=2.15$ $(1.27,3.62))$ and who reported a working hour of $8-12$ hours per day were two times $(\mathrm{AOR}=2.09(1.18,3.70))$ more likely to have adequate knowledge as compared to nurses who reported a working hour of $>12$ hours per day.

Moreover, nurses who have years of experience of $>5$ years were nearly six times more likely $(\mathrm{AOR}=5.59$ (2.86-10.94)), those who have years of experience of 3-5 years were nearly four times more likely $(\mathrm{AOR}=3.99$ (2.05-7.79)), and those who have years of experience of 1-3 years were two times more likely $(\mathrm{AOR}=2.19(1.20-4.00))$ to have adequate knowledge as compared to those nurses who reported years of experience of less than one year (Table 5). 
TABLE 3: Knowledge of nurses regarding nonpharmacological pain management among nurses working at Amhara region Comprehensive Specialized Hospitals, Ethiopia, in $2021(n=775)$.

\begin{tabular}{|c|c|c|c|c|}
\hline \multirow{2}{*}{ Statements } & \multicolumn{2}{|c|}{ Yes } & \multicolumn{2}{|c|}{ No } \\
\hline & $N$ & $P$ & $N$ & $P$ \\
\hline The most accurate judge of the intensity of the patient's pain is the patient himself & 663 & 85.5 & 112 & 14.5 \\
\hline Providing a suitable room temperature and good air conditioning can alleviate pain & 680 & 87.7 & 95 & 12.3 \\
\hline Providing the patient with a possibility to rest by minimizing noise can alleviate pain & 666 & 85.9 & 109 & 14.1 \\
\hline Involving families in pain management can increase a patient's ability to manage pain & 617 & 79.6 & 158 & 20.4 \\
\hline Using nonpharmacological pain management has no value to the patient & 168 & 21.7 & 607 & 78.3 \\
\hline Encouraging patients to relax different parts of their bodies alleviates the sensation of pain & 670 & 86.5 & 105 & 13.5 \\
\hline Try to focus a patient's thoughts/attention away from pain can decrease pain & 639 & 82.5 & 136 & 17.5 \\
\hline Vital signs are always reliable indicators of the intensity of a patient's pain & 362 & 46.7 & 413 & 53.3 \\
\hline Asking patients to suggest ways to relieve pain can increase the patient's ability to manage pain & 639 & 82.5 & 136 & 17.5 \\
\hline Patients who can be distracted from pain usually do not have severe pain & 302 & 39 & 473 & 61 \\
\hline Nonpharmacological interventions are effective only for mild pain control & 495 & 63.9 & 280 & 36.1 \\
\hline The patient's pain can be alleviated by position changes & 626 & 80.8 & 149 & 19.2 \\
\hline The benefit of nonpharmacological pain management is that it has fewer side effects than drugs & 293 & 37.8 & 482 & 62.2 \\
\hline Patients who can be distracted from pain usually do not have pain & 222 & 28.6 & 553 & 71.4 \\
\hline Distraction, for example, by the use of music or relaxation, can decrease the perception of pain & 650 & 83.9 & 125 & 16.1 \\
\hline $\begin{array}{l}\text { Patients with chronic pain should receive pain medications along with nonpharmacological interventions at regular } \\
\text { intervals with or without the presence of discomfort }\end{array}$ & 540 & 69.7 & 235 & 30.3 \\
\hline The patient should be advised to use nonpharmacological means alone rather than medications & 382 & 49.3 & 393 & 50.7 \\
\hline Nonpharmacological methods of pain relief have no applications for neonates & 308 & 39.7 & 467 & 60.3 \\
\hline Nonpharmacological pain management only includes massage, heat/cold and relaxation & 319 & 41.2 & 456 & 58.8 \\
\hline It may often be useful to give a placebo to assess whether a patient in pain is genuinely in pain & 396 & 51.1 & 379 & 48.9 \\
\hline
\end{tabular}

$N=$ frequency; $P=$ percent.

TABLE 4: Attitude of nurses towards nonpharmacological pain management among nurses working at Amhara region Comprehensive Specialized Hospitals, Ethiopia, in $2021(N=775)$.

\begin{tabular}{|c|c|c|c|c|c|}
\hline Question & SD & $\mathrm{D}$ & $\mathrm{N}$ & A & SA \\
\hline Pain cannot be seen in the patient's behavior & 346 & 175 & 92 & 101 & 61 \\
\hline Nonpharmacological therapies should be given to sick people & 71 & 116 & 119 & 203 & 266 \\
\hline Distraction increases the intensity of pain & 288 & 156 & 131 & 150 & 50 \\
\hline Nondrug interventions are very effective for severe pain than mild to moderate pain & 291 & 199 & 112 & 114 & 59 \\
\hline $\begin{array}{l}\text { Using pain assessment tools usually makes nursing more complicated and consumes time for other ward } \\
\text { activities }\end{array}$ & 228 & 190 & 139 & 135 & 83 \\
\hline Nurses are best judges of the patient's pain intensity than doctors because they spend 24 hours with the patient & 65 & 84 & 85 & 162 & 379 \\
\hline $\begin{array}{l}\text { Nonpharmacological pain management education received during nurse training is adequate for effective pain } \\
\text { management after graduation }\end{array}$ & 238 & 182 & 128 & 142 & 85 \\
\hline The nurse's role during nondrug pain management is to follow only the doctor's orders & 343 & 193 & 100 & 94 & 45 \\
\hline Are you willing to provide information related to nondrug methods to patients? & 51 & 93 & 126 & 255 & 250 \\
\hline Are you willing to provide nonpharmacological methods to people who have pain? & 50 & 86 & 118 & 253 & 268 \\
\hline It is not advised to use both pharmacological and nonpharmacological methods together & 356 & 152 & 89 & 108 & 70 \\
\hline Preparing a patient for a procedure by explaining the procedure can decrease pain & 68 & 110 & 102 & 225 & 270 \\
\hline Encouraging a patient in pain to think about pleasant and positive matters can relieve pain & 47 & 84 & 119 & 262 & 263 \\
\hline Teaching patients about the correct breathing technique cannot alleviate his/her pain & 263 & 188 & 130 & 133 & 61 \\
\hline Encouraging the patient by rewarding verbally cannot alleviate his/her pain & 242 & 218 & 144 & 124 & 47 \\
\hline Encouraging the patient to relax different parts of his body can alleviate pain & 42 & 95 & 104 & 246 & 288 \\
\hline Internal decoration of units does not affect the patient's ability to manage pain & 225 & 255 & 122 & 105 & 68 \\
\hline $\begin{array}{l}\text { Are you willing to encourage family members to bring some of the patient's belongings (pictures, pillows, etc.) to } \\
\text { the unit? }\end{array}$ & 56 & 78 & 116 & 225 & 300 \\
\hline
\end{tabular}

$\mathrm{SD}=$ strongly disagree; $\mathrm{D}=$ disagree; $\mathrm{N}=$ neutral; $\mathrm{A}=$ agree; $\mathrm{SA}=$ strongly agree.

3.6. Factors Associated with Nurses' Attitude. In bivariable logistic regression analysis, age, monthly income, educational qualification, year of experience, previous education on nonpharmacological pain management, working unit, nurse-to-patient ratio, workload, lack of evidence, working hours, and adequate knowledge were significantly associated with attitude. In multivariable analysis, only monthly income, nurse-to-patient ratio, and knowledge were significantly associated.

Those nurses who have a monthly income greater than 8017 Ethiopian birr were four times more likely $(\mathrm{AOR}=4.38$ $(1.64,11.69))$, nurses who have a monthly income of 7071-8017 Ethiopian birr were five times more likely $($ AOR $=5.36(2.78,10.33))$, and nurses who have a monthly 
TABLE 5: Factors associated with nurses' knowledge regarding nonpharmacological pain management among nurses working at Amhara region Comprehensive Specialized Hospitals, Ethiopia, in $2021(N=775)$.

\begin{tabular}{|c|c|c|c|c|c|c|}
\hline \multirow{2}{*}{ Variables } & \multirow{2}{*}{ Category } & \multicolumn{2}{|c|}{ Knowledge } & \multirow{2}{*}{ COR $(95 \% \mathrm{CI})$} & \multirow{2}{*}{ AOR (95\% CI) } & \multirow{2}{*}{$p$ value } \\
\hline & & Adequate & Inadequate & & & \\
\hline \multirow[t]{2}{*}{ Age (years) } & $<31$ & 208 & 247 & 1 & 1 & \\
\hline & $>31$ & 212 & 108 & $2.33(1.73,3.13)$ & $1.42(0.95,2.14)$ & 0.084 \\
\hline \multirow[t]{2}{*}{ Sex } & Male & 118 & 144 & $1.18(0.89,1.58)$ & $1.37(0.95,1.97)$ & 0.088 \\
\hline & Female & 232 & 211 & 1 & 1 & \\
\hline \multirow[t]{5}{*}{ Monthly income (ETB) } & $<5358$ & 123 & 219 & 1 & 1 & \\
\hline & $5358-6193$ & 64 & 46 & $2.47(1.593 .84)$ & $0.78(0.41,1.45)$ & 0.433 \\
\hline & $6193-7071$ & 100 & 51 & $3.49(2.33,5.22)$ & $0.57(0.29,1.13)$ & 0.112 \\
\hline & $7071-8017$ & 85 & 28 & $5.40(3.34,8.74)$ & $1.85(0.95,3.58)$ & 0.068 \\
\hline & $>8017$ & 48 & 11 & $7.76(3.89,15.51)$ & $1.08(0.39,2.99)$ & 0.870 \\
\hline \multirow[t]{3}{*}{ Educational qualification } & Diploma & 63 & 162 & 1 & 1 & \\
\hline & $\mathrm{BSc}$ & 284 & 178 & $4.10(2.92,5.79)$ & $2.86(1.80,4.56)^{*}$ & $<0.001$ \\
\hline & MSc & 73 & 15 & $12.51(6.68,23.43)$ & $3.51(1.37,8.99)^{*}$ & 0.009 \\
\hline \multirow[t]{4}{*}{ Years of experience } & $<1$ year & 35 & 105 & 1 & 1 & \\
\hline & $1-3$ years & 57 & 87 & $1.96(1.18,3.26)$ & $2.19(1.20,4.00)^{*}$ & 0.010 \\
\hline & $3-5$ years & 76 & 57 & $4.00(2.39,6.68)$ & $3.99(2.05,7.79)^{*}$ & $<0.001$ \\
\hline & $>5$ years & 252 & 106 & $7.13(4.57,11.12)$ & $5.59(2.86,10.94)^{*}$ & $<0.001$ \\
\hline \multirow[t]{2}{*}{ Education on NPPM } & Yes & 263 & 194 & $1.39(1.04,1.85)$ & $1.11(0.77,1.59)$ & 0.564 \\
\hline & No & 157 & 161 & 1 & 1 & \\
\hline \multirow[t]{2}{*}{ Need to have education on NPPM } & Yes & 321 & 257 & $1.23(0.89,1.70)$ & $1.31(0.86,2.02)$ & 0.205 \\
\hline & No & 99 & 98 & 1 & 1 & \\
\hline \multirow[t]{10}{*}{ Working unit } & Pediatrics & 61 & 85 & 1 & 1 & \\
\hline & Oncology & 8 & 6 & $1.86(0.80,7.85)$ & $2.08(0.50,8.71)$ & 0.312 \\
\hline & OPD & 64 & 87 & $1.02(0.64,1.62)$ & $1.41(0.80,2.47)$ & 0.227 \\
\hline & Emergency & 63 & 27 & $3.25(1.86,5.68)$ & $5.10(2.57,10.11)^{*}$ & $<0.001$ \\
\hline & $\mathrm{OR}$ & 38 & 38 & $1.39(0.79,2.43)$ & $1.18(0.61,2.29)$ & 0.614 \\
\hline & Orthopedic & 26 & 12 & $3.01(1.41,6.44)$ & $5.61(2.25,13.96)^{*}$ & $<0.001$ \\
\hline & Recovery & 23 & 9 & $3.56(1.54,8.23)$ & $2.05(0.76,5.57)$ & 0.156 \\
\hline & ICU & 43 & 15 & $3.99(2.03,7.83)$ & $3.06(1.38,6.77)$ & 0.006 \\
\hline & Medical & 55 & 62 & $1.23(0.75,2.01)$ & $1.41(0.77,2.58)$ & 0.252 \\
\hline & Surgical & 38 & 15 & $3.53(1.78,6.98)$ & $5.29(2.32,12.05)^{*}$ & $<0.001$ \\
\hline \multirow[t]{4}{*}{ Nurse-to-patient ratio } & $1: 4$ & 175 & 61 & $3.17(2.19,4.58)$ & $2.33(1.44,3.78)^{*}$ & 0.001 \\
\hline & $1: 6$ & 52 & 47 & $1.22(0.77,1.92)$ & $1.05(0.60,1.84)$ & 0.857 \\
\hline & $1: 8$ & 51 & 90 & $0.62(0.41,0.94)$ & $0.38(0.22,0.64)^{*}$ & $<0.001$ \\
\hline & Undetermined & 142 & 157 & 1 & 1 & \\
\hline \multirow[t]{2}{*}{ Presence of workload } & Yes & 248 & 276 & $0.41(0.30,0.56)$ & $0.63(0.42,0.972)$ & 0.036 \\
\hline & No & 172 & 79 & 1 & 1 & \\
\hline \multirow[t]{2}{*}{ Lack of evidence } & Yes & 186 & 214 & $0.52(0.39,0.69)$ & $0.835(0.57,1.20)$ & 0.335 \\
\hline & No & 234 & 141 & 1 & 1 & \\
\hline \multirow[t]{3}{*}{ Working hours per day } & 8 hours & 252 & 179 & $2.19(1.46,3.28)$ & $2.15(1.27,3.62)^{*}$ & 0.004 \\
\hline & $8-12$ hours & 118 & 98 & $1.87(1.20,2.93)$ & $2.09(1.18,3.70)^{*}$ & 0.011 \\
\hline & $>12$ hours & 50 & 78 & 1 & 1 & \\
\hline \multirow[t]{2}{*}{ Ever used NPPM? } & Yes & 346 & 275 & $1.36(0.95,1.93)$ & $1.24(0.79,1.93)$ & 0.336 \\
\hline & No & 74 & 80 & 1 & 1 & \\
\hline \multirow[t]{2}{*}{ On-the-job training? } & Yes & 132 & 88 & $1.391(1.01,1.90)$ & $0.98(0.64,1.49)$ & 0.945 \\
\hline & No & 288 & 267 & 1 & 1 & \\
\hline
\end{tabular}

Note. Statistical significance: ${ }^{*} p$ value $<0.05$.

income of 6193-7071 Ethiopian birr were three times more likely $(\mathrm{AOR}=3.19(1.65,6.16))$ to have favorable attitude compared with those nurses who had monthly income less than 5346 Ethiopian birr.
Moreover, those nurses who reported a nurse-to-patient ratio of $1: 4$ in their working unit were two times more likely $(\mathrm{AOR}=1.89(1.19,3.01))$ to have a positive attitude as compared to those who reported an undetermined nurse-to-patient 
TABLE 6: Factors associated with nurses' attitude towards nonpharmacological pain management among nurses working at Amhara region Comprehensive Specialized Hospitals, Ethiopia, in $2021(N=775)$.

\begin{tabular}{|c|c|c|c|c|c|c|}
\hline \multirow{2}{*}{ Variables } & \multirow{2}{*}{ Category } & \multicolumn{2}{|c|}{ Attitude } & \multirow{2}{*}{ COR $(95 \% \mathrm{CI})$} & \multirow{2}{*}{ AOR $(95 \% \mathrm{CI})$} & \multirow{2}{*}{$p$ value } \\
\hline & & Favorable & Unfavorable & & & \\
\hline \multirow[t]{2}{*}{ Age (years) } & $<31$ & 200 & 255 & 1 & 1 & \\
\hline & $>31$ & 186 & 134 & $1.77(1.32,2.36)$ & $1.24(0.84,1.84)$ & 0.266 \\
\hline \multirow[t]{5}{*}{ Monthly income (ETB) } & $<5358$ & 111 & 231 & 1 & 1 & \\
\hline & $5358-6193$ & 55 & 55 & $2.08(1.34,3.22)$ & $1.26(0.68,2.33)$ & 0.455 \\
\hline & $6193-7071$ & 93 & 58 & $3.33(2.24,4.97)$ & $3.19(1.65,6.16)^{*}$ & 0.001 \\
\hline & $7071-8017$ & 82 & 31 & $5.50(3.43,8.81)$ & $5.36(2.78,10.33)^{*}$ & $<0.001$ \\
\hline & $>8017$ ETB & 45 & 14 & $6.68(3.52,12.70)$ & $4.38(1.64,11.69)^{*}$ & 0.003 \\
\hline \multirow[t]{3}{*}{ Educational qualification } & Diploma & 75 & 150 & 1 & 1 & \\
\hline & $\mathrm{BSc}$ & 243 & 219 & $2.21(1.59,3.09)$ & $0.82(0.52,1.29)$ & 0.395 \\
\hline & MSc & 68 & 20 & $6.80(3.84,12.02)$ & $0.83(0.33,2.04)$ & 0.687 \\
\hline \multirow[t]{4}{*}{ Years of experience } & $<1$ year & 42 & 98 & 1 & 1 & \\
\hline & $1-3$ years & 55 & 89 & $1.44(0.88,2.36)$ & $0.99(0.55,1.77)$ & 0.989 \\
\hline & $3-5$ years & 77 & 56 & $3.20(1.94,5.28)$ & $1.84(0.96,3.52)$ & 0.062 \\
\hline & $>5$ years & 212 & 146 & $3.38(2.23,5.14)$ & $0.72(0.38,1.36)$ & 0.321 \\
\hline \multirow[t]{2}{*}{ Education on NPPM } & Yes & 222 & 193 & $1.37(1.03,1.82)$ & $1.25(0.88,1.76)$ & 0.204 \\
\hline & No & 164 & 196 & 1 & 1 & \\
\hline \multirow[t]{2}{*}{ Need to have NPPM education } & Yes & 298 & 280 & $1.31(0.95,1.82)$ & $1.38(0.92,2.07)$ & 0.119 \\
\hline & No & 88 & 109 & 1 & 1 & \\
\hline \multirow[t]{10}{*}{ Working unit } & Pediatrics & 67 & 79 & 1 & 1 & \\
\hline & Oncology & 8 & 6 & $1.57(0.88,9.83)$ & $2.22(0.52,9.37)$ & 0.275 \\
\hline & OPD & 74 & 77 & $1.13(0.71,1.78)$ & $1.35(0.78,2.34)$ & 0.280 \\
\hline & Emergency & 42 & 48 & $1.03(0.60,1.74)$ & $0.67(0.35,1.29)$ & 0.241 \\
\hline & OR & 34 & 42 & $0.95(0.54,1.66)$ & $0.72(0.37,1.40)$ & 0.334 \\
\hline & Orthopedic & 23 & 15 & $1.80(0.87,3.74)$ & $1.89(0.78,4.59)$ & 0.158 \\
\hline & Recovery & 19 & 13 & $1.72(0.79,3.59)$ & $0.80(0.32,2.01)$ & 0.649 \\
\hline & ICU & 36 & 22 & $1.92(1.03,1.64)$ & $0.97(0.46,2.05)$ & 0.954 \\
\hline & Medical & 54 & 63 & $1.01(0.62,2.29)$ & $1.01(0.55,1.84)$ & 0.970 \\
\hline & Surgical & 27 & 26 & $1.22(0.65,2.29)$ & $0.87(0.41,1.86)$ & 0.736 \\
\hline \multirow[t]{4}{*}{ Nurse-to-patient ratio } & $1: 4$ & 165 & 71 & $2.90(2.02,4.15)$ & $1.89(1.19,3.01)^{*}$ & 0.007 \\
\hline & $1: 6$ & 45 & 54 & $1.04(0.65,1.64)$ & $0.96(0.56,1.65)$ & 0.893 \\
\hline & $1: 8$ & 43 & 98 & $0.54(0.35,0.83)$ & $0.56(0.34,0.94)$ & 0.029 \\
\hline & Undetermined & 133 & 166 & 1 & 1 & \\
\hline \multirow[t]{2}{*}{ Work load } & Yes & 239 & 307 & $0.43(0.31,0.59)$ & $0.70(0.47,1.06)$ & 0.097 \\
\hline & No & 147 & 82 & 1 & 1 & \\
\hline \multirow[t]{2}{*}{ Lack of evidence } & Yes & 179 & 221 & $0.65(0.49,0.87)$ & $0.99(0.69,1.42)$ & 0.979 \\
\hline & No & 207 & 168 & 1 & 1 & \\
\hline \multirow[t]{3}{*}{ Working hours } & 8 hours & 227 & 204 & $1.52(1.02,2.27)$ & $0.88(0.53,1.44)$ & 0.617 \\
\hline & $8-12$ hours & 105 & 111 & $1.29(0.83,2.01)$ & $0.86(0.50,1.47)$ & 0.591 \\
\hline & $>12$ hours & 54 & 74 & 1 & 1 & \\
\hline \multirow[t]{2}{*}{ Knowledge } & Adequate & 291 & 129 & $6.17(4.51,8.44)$ & $4.26(2.91,6.24)^{*}$ & $<0.001$ \\
\hline & Inadequate & 95 & 260 & 1 & 1 & \\
\hline
\end{tabular}

Note. Statistical significance: ${ }^{*} p$ value $<0.05$.

ratio in their working unit. Furthermore, nurses who have adequate knowledge were four times more likely $(\mathrm{AOR}=4.26$ $(2.91,6.24))$ to have a favorable attitude (Table 6).

\section{Discussion}

This study was conducted to assess nurses' knowledge, attitude, and associated factors towards nonpharmacological pain management. The study revealed that $54.2 \%$ (95\% CI: $50.6,57.9)$ of nurses had adequate knowledge regarding nonpharmacological pain management with a total median knowledge score of 14 . This finding is consistent with studies conducted in Benishangul-Gumuz (51.2\%) [8] and Addis Ababa Black Lion Hospital (52\%) [20].

The result of this study is lower than a study conducted in Saudi Arabia (87.5\%) [17]. The variation might be due to the differences in nursing curriculum regarding nonpharmacological pain management, sources of information, continuous and sustainable on-the-job training programs, and variations in technological advancement in the two countries.

But the result of this study is higher than a study conducted in Zimbabwe where $48.6 \%$ of the study participants had adequate knowledge [21]. The difference might be 
due to the variation in educational status. In a study conducted in Zimbabwe, about $58.7 \%$ of the study participants were diploma holders, but in this study, more than half (59.6\%) of the study participants are degree holders, whereas diploma holders are only $29 \%$ of the total participants.

Regarding attitude, this study revealed that $49.8 \%$ of nurses (95\% CI: 46.1, 53.2) had a favorable attitude towards nonpharmacological pain management with a total median attitude score of $70 \%$. The result of this study is in line with a study conducted in Benishangul-Gumuz, Ethiopia (47\%) [8].

The finding of this study is lower compared with a study conducted in Saudi Arabia (85\%) [17]. These variations may be due to differences in perceptions of the study participants towards nonpharmacological pain management. Moreover, the possible justification might be due to the difference in the cutoff point of the scores regarding the attitude-related tool. That is, in this study, the cutoff point for a favorable attitude was $\geq 63$, whereas the cutoff point for a favorable attitude in Saudi Arabia was $>60$ [17].

This finding is higher as compared with a study conducted in Addis Ababa Black Lion Hospital which revealed that $34.6 \%$ of the study participants had a favorable attitude towards nonpharmacological pain management [20]. The possible justification for this could be due to a difference in sample size (i.e., the sample size for this study is 845 whereas the sample size for the study done in Addis Ababa was 269).

Educational status, year of experience, working unit, nurse-to-patient ratio, and working hours per day were the factors significantly associated with knowledge.

Nurses who had master's degrees were nearly four times more likely, and BSc nurses were about three times more likely to have adequate knowledge as compared to diploma nurses. This is similar to studies conducted in BenishangulGumuz [8], Eritrea [22], Saudi Arabia [17], China [23], and the USA [24]. The possible justification for this could be that as nurses' educational status increases, they could have a higher probability of getting up-to-date information regarding nonpharmacological pain management, as well as they might have a higher chance to review different kinds of literature regarding the topic and are more likely to apply their knowledge in practice to treat the patient's pain.

This finding is supported by studies conducted in Turkey, Iran, and Norway that shows that nurses who were degree bachelorette and above had more theoretical and clinical knowledge regarding pain and its management than nondegree bachelorette nurses. Furthermore, they had more experience in clinical practice [25-27].

Nurses with experience of $>5$ years, 3-5 years, and 1-3 years were six times, four times, and two times more likely to have adequate knowledge, respectively, compared with nurses who have less than 1 year of experience. This study is supported by the studies conducted in Benishangul-Gumuz [8], Zimbabwe [21], Saudi Arabia [17], Norway [27], China [28], and the United States [24]. The possible justification for this could be that when the nurses have many years of experience, their exposure to clinical practice becomes long, which might allow them to communicate with their colleagues, share information, and acquire knowledge regarding nonpharmacological pain management.
Working unit is the other facility-related variable significantly associated with nurses' knowledge. Nurses who work in orthopedics, surgical, emergency, and ICU were nearly six, five, five, and three times more likely to have adequate knowledge, respectively, as compared with nurses who work in pediatric units. This finding is supported by a study conducted in Turkey [26]. The possible justification for this finding could be that nurses working in orthopedic wards, surgical wards, and emergency wards might be more exposed to pain as compared to nurses working in pediatric units. Furthermore, according to statistics in Ethiopia, most commonly patients who are admitted to the orthopedic and surgical wards are adults, so those patients are more capable of complaining their feelings of pain to nurses verbally at any time as compared to pediatric patients. These might enable nurses to communicate with their colleagues and physicians regarding different modalities of pain management. It also enables them to read recent journals to update their knowledge.

In this finding, nurse-to-patient ratio was significantly associated with nurses' knowledge. Those nurses who reported a nurse-to-patient ratio of $1: 4$ are more than two times more likely to have adequate knowledge as compared to those nurses who reported an undetermined nurse-topatient ratio. This finding is supported by studies conducted in Benishangul-Gumuz [8] and Uganda [29]. The possible reason for this could be that when there is a higher nurse-topatient ratio, nurses might have a workload and they might not get enough time to update their knowledge, and nurseto-patient interaction will become very limited, which makes nurses underestimate the patient's pain.

Working hours is another significantly associated factor with knowledge. Those nurses working eight hours per day were two times more likely to have adequate knowledge as compared with nurses who work more than 12 hours per day. This finding is supported by a study conducted in Saudi Arabia [17]. The possible justification could be that while nurses work more than 12 hours per day, they could become more tired and loaded. As a result, they might have no adequate time to update their knowledge.

Regarding factors associated with attitude, this study revealed that monthly income, nurse-to-patient ratio, and knowledge were significantly associated. Those nurses who have a monthly income of $>8017$ Ethiopian birr, 7071-8017 Ethiopian birr, and 6193-7071 Ethiopian birr were four times, five times, and three times more likely to have a favorable attitude, respectively, compared with nurses having a monthly income of less than 5358 ETB. The reason for this relationship could be because most of the time, nurses who have a relatively higher monthly income are those who have higher educational qualifications and many years of experience in nursing practice. That means these nurses could get adequate knowledge regarding nonpharmacological pain management, and they could have a favorable attitude. Moreover, nurses who have higher monthly income may afford to buy electronic products like laptop computers and smartphones, so they might access available professional-related information at their fingertips and update their knowledge. 
Those nurses who reported a nurse-to-patient ratio of 1 : 4 are about two times more likely to have a favorable attitude as compared to nurses who reported an undetermined nurse-to-patient ratio. The finding of this study is supported by the studies conducted in Benishangul-Gumuz and Australia $[8,30]$. The possible reason for this could be that as the nurse-to-patient ratio increases, nurses become challenged by workload and shortage of time, and this could not enable them to read more about nonpharmacological pain management, and their attitude could be changed.

Knowledge was another factor significantly associated with attitude. Those nurses who have adequate knowledge were four times more likely to have a favorable attitude towards nonpharmacological pain management as compared to nurses who have inadequate knowledge. This finding is supported by the studies conducted in Benishangul-Gumuz [8], Saudi Arabia [17], and Turkey [26]. This could be because nurses who have adequate knowledge might have enough information regarding the benefits of nonpharmacological pain management over pharmacological pain management, and this could lead nurses to have a favorable attitude.

\section{Limitations of the Study}

In this study, qualitative data collection methods were not used. The results of the study might be affected by information bias. Responses might not accurately show the attitude of nurses because the questionnaire has a selfreporting nature.

\section{Conclusion}

More than half and nearly half of the nurses had adequate knowledge and a favorable attitude towards nonpharmacological pain management, respectively. Educational qualification, years of experience, working unit, nurseto-patient ratio, and working hours per day were significantly associated with a nurse's knowledge. Monthly income, nurse-to-patient ratio, and nurse's knowledge were significantly associated with the attitudes of nurses.

\section{Abbreviations}

AOR: Adjusted odd ratio

CI: $\quad$ Confidence interval

DBCSH: Debreberhan Comprehensive Specialized Hospital

DMCSH: Debre Tabor Comprehensive Specialized Hospital

DCSH: Dessie Comprehensive Specialized Hospital

DMCSH: Debre Markos Comprehensive Specialized Hospital

ETB: $\quad$ Ethiopian birr

FHCSH: Felege-Hiwot Comprehensive Specialized Hospital

GUCSH: Gondar University Comprehensive Specialized Hospital

IQR: Interquartile range
NPPM: Nonpharmacological pain management

OR: $\quad$ Odds ratio

TGCSH: Tibebe-Ghion Comprehensive Specialized Hospital.

\section{Data Availability}

All data are available from the corresponding author upon reasonable request.

\section{Ethical Approval}

The study was carried out after the approval was obtained from the Ethical Review Committee of the University of Gondar, College of Medicine and Health Sciences, on behalf of the Institutional Review Board (IRB).

\section{Consent}

Permission letters were obtained from the management committees of the selected hospitals. Written consent was obtained from the respondents before administrating the questionnaire, and participants were assured of the confidentiality of the information, and the data was collected anonymously. Any inconvenience to participants during data collection was minimized.

\section{Conflicts of Interest}

The authors declare that they have no conflicts of interest.

\section{Authors' Contributions}

All authors made substantial contributions to conception and design, acquisition of data, or analysis, and interpretation of data; took part in drafting the article or revising it critically for important intellectual content; agreed to submit to the current journal; gave final approval of the version to be published; and agreed to be accountable for all aspects of the work.

\section{Acknowledgments}

The authors acknowledge the University of Gondar, all hospital directors in the Amhara region, data collectors, supervisors, and study participants.

\section{References}

[1] T. S. Jensen, R. Baron, M. Haanpää et al., "A new definition of neuropathic pain,” Pain, vol. 152, no. 10, pp. 2204-2205, 2011.

[2] S. N. Raja, D. B. Carr, M. Cohen et al., "The revised International Association for the Study of Pain definition of pain: concepts, challenges, and compromises," Pain, vol. 161, no. 9, pp. 1976-1982, 2020.

[3] J. Park, C. E. Hirz, K. Manotas, and N. Hooyman, "Nonpharmacological pain management by ethnically diverse older adults with chronic pain: barriers and facilitators," Journal of Gerontological Social Work, vol. 56, no. 6, pp. 487-508, 2013.

[4] A. El Geziry, Y. Toble, F. Al Kadhi, M. Pervaiz, and M. Al Nobani, "Non-pharmacological pain management," Pain 
Management in Special Circumstances, pp. 1-14, IntechOpen, London, UK, 2018.

[5] E. Mwanza, R. D. Gwisai, and C. Munemo, "Knowledge on nonpharmacological methods of pain management among nurses at Bindura Hospital, Zimbabwe," Pain Research and Treatment, vol. 2019, Article ID 2703579, 8 pages, 2019.

[6] D. L. Heath, "Nurses' knowledge and attitudes concerning pain management in an Australian hospital," Australian Journal of Advanced Nursing: A Quarterly Publication of the Royal Australian Nursing Federation, vol. 16, no. 2, pp. 15-18, 1998.

[7] R. Kheshti, S. Namazi, M. Mehrabi, and D. Firouzabadi, "Health care workers' knowledge, attitude, and practice about chronic pain management, Shiraz, Iran," Anesthesiology and Pain Medicine, vol. 6, no. 4, 2016.

[8] L. Jira, N. Weyessa, S. Mulatu, and A. Alemayehu, "Knowledge and attitude towards non-pharmacological pain management and associated factors among nurses working in benishangul Gumuz regional state hospitals in western Ethiopia, 2018," Journal of Pain Research, vol. 13, pp. 2917-2927, 2020.

[9] N. Karabulut, D. Gürçayir, and Y. Yaman Aktaş, "Nonpharmacological interventions for pain management used by nursing students in Turkey," Kontakt, vol. 18, no. 1, pp. e22-e29, 2016.

[10] A. Ung, Y. Salamonson, W. Hu, and G. Gallego, “Assessing knowledge, perceptions and attitudes to pain management among medical and nursing students: a review of the literature," British Journal of Pain, vol. 10, no. 1, pp. 8-21, 2016.

[11] C. W. Dewey and R. C. Da Costa, Practical Guide to Canine and Feline Neurology, John Wiley \& Sons, Hoboken, NJ, USA, 2015.

[12] J. C. Ballantyne, "The brain on opioids," Pain, vol. 159, no. 1, pp. S24-S30, 2018.

[13] F. Merz, "United nations office on drugs and crime: world drug report 2017," SIRIUS-Zeitschrift für Strategische Analysen, vol. 2, no. 1, pp. 85-86, 2018.

[14] A. Bryman, Social Research Methods, Oxford University Press, Oxford, UK, 2016.

[15] P. Katonis, A. Kampouroglou, A. Aggelopoulos et al., "Pregnancy-related low back pain," Hippokratia, vol. 15, no. 3, pp. 205-10, 2011.

[16] ARHB, "Amhara National Regional Health Bureau: 9 month performance report," 2020.

[17] H. S. Ali, Y. Ibrahim, and E. Mohamed, "Non-pharmacological pain management: nurses' knowledge, attitudes and practices in selected hospitals at Makkah El-Mukarramah," Life Science Journal, vol. 2, no. 10, 2013.

[18] C. Munemo, Knowledge on Non-pharmacological Methods of Pain Management among Nurses at Bindura Hospital, BUSE, Bindura, Zimbabwe, 2015.

[19] B. R. Ferrell and M. McCaffery, "Knowledge and attitudes survey regarding pain," 2008.

[20] S. Sisay, Assessments of Nurses Knowledge, Attitude and Practice Regarding Non-pharmacological Pain Management and Associated Factors at Tikur Anbessa Hospital, in Addis Ababa, Ethiopia, 2017, Addis Ababa University, Addis Ababa, Ethiopia, 2017.

[21] A. Manwere, T. Chipfuwa, M. M. Mukwamba, and G. Chironda, "Knowledge and attitudes of registered nurses towards pain management of adult medical patients: a case of Bindura hospital," Health Science Journal, vol. 9, no. 4, p. 1, 2015.
[22] B. Y. Kidanemariam, T. Elsholz, L. L. Simel, E. H. Tesfamariam, and Y. M. Andemeskel, "Utilization of non-pharmacological methods and the perceived barriers for adult postoperative pain management by the nurses at selected National Hospitals in Asmara, Eritrea," BMC Nursing, vol. 19, no. 1, pp. 100-110, 2020.

[23] M. M. Y. Tse and B. S. H. Chan, "Knowledge and attitudes in pain management," Journal of Pain \& Palliative Care Pharmacotherapy, vol. 18, no. 1, pp. 47-58, 2004.

[24] J. T. Moceri and D. J. Drevdahl, "Nurses' knowledge and attitudes toward pain in the emergency department," Journal of Emergency Nursing, vol. 40, no. 1, pp. 6-12, 2014.

[25] F. Asadi-Noghabi, M. Tavassoli-Farahi, H. Yousefi, and T. Sadeghi, "Neonate pain management: what do nurses really know?" Global Journal of Health Science, vol. 6, no. 5, p. 284, 2014.

[26] A. Yava, H. Çicek, N. Tosun, C. Özcan, D. Yildiz, and B. Dizer, "Knowledge and attitudes of nurses about pain management in Turkey," International Journal of Caring Sciences, vol. 6, no. 3, 2013.

[27] A. H. Smeland, A. Twycross, S. Lundeberg, and T. Rustøen, "Nurses' knowledge, attitudes and clinical practice in pediatric postoperative pain management," Pain Management Nursing, vol. 19, no. 6, pp. 585-598, 2018.

[28] Y.-c Kam, "Medical nurses' knowledge, attitudes and barriers in pain management," Degree Thesis of the University of Hong Kong, Hong Kong, 2007.

[29] I. B. Kizza, Nurses' Knowledge and Practices Related to Pain Assessment in Critically Ill Patients at Mulago Hospital, Uganda, Muhimbili University of Health and Allied Sciences, Dar es Salaam, Tanzania, 2012.

[30] V. Poulton, A. Hobman, L. Berggren, P. Nash, S. Helmrich, and P. Yates, "Factors influencing nurses' decisions to use non-pharmacological therapies to manage patients' pain," Australian Journal of Advanced Nursing, vol. 19, no. 1, p. 27, 2001. 